\title{
Double trouble: diagnostic dilemma in a rare association of proximal ureteric valve with orthotopic ureterocele-case report
}

\author{
Anuj Dumra, P. Ashwin Shekar * (10) and Hardik Patel
}

\begin{abstract}
Background: Association of the ureterocele and proximal ureteral valve is a rare congenital anomaly which can lead to quick detoriation of renal function due to double obstruction. Though ureteral valves have been associated with other ureteral anomalies, this specific association is extremely rare.

Case presentation: A 7-month-old boy was referred to us for antenatally detected hydronephrosis. Provisional diagnosis of orthotopic ureterocele with pelviureteric junction (PUJ) obstruction was made based on preoperative imaging. Endoscopic incision of ureterocele was done and retrograde pyelography showed tight obstruction at PUJ which necessitated a pyeloplasty. Examination of resected specimen confirmed a ureteral valve. Postoperatively, the patient had good improvement in kidney function.

Conclusion: To conclude, congenital ureteral valves are a rare cause of ureteric obstruction and its association with ureterocele is rarer still. Identification of an ureterocele should not deter us from searching for an associated pathology like a ureteric valve when imaging shows more severe hydronephrosis suggestive of more proximal obstruction.
\end{abstract}

Keywords: Ureterocele, Ureteric valve, Association, Case report

\section{Background}

Ureteral valves are a rare clinical finding. Frequently, they are associated with other urological anomalies such as complete or incomplete renal duplication, ectopic ureter, vesico-ureteral reflux and horseshoe kidney $[1,2]$. Hydronephrosis is the most common clinical sign. Clinical association of ureteric valve with orthotopic ureterocele, which by definition is acystic dilatation of the terminal ureter contained within the confines of the bladder, in infancy is extremely rare and has not been reported before. The case of ureteric valve reported herein evokes interest from the point of view of its hitherto unreported association with ureterocele and the diagnostic dilemma involved in the proper diagnosis of this double pathology.

\footnotetext{
*Correspondence: ashwindoc1@yahoo.com

Department of Urology, Sri Sathya Sai Institute of Higher Medical

Sciences, Prashantigram, Puttaparthi, Andhra Pradesh 515134, India
}

\section{Case presentation}

A 7-month-old boy presented to us with antenatally detected left hydroureteronephrosis after an uncomplicated gestation along with straining to void and poor stream. Physical examination was unremarkable except for phimosis. Urine examination showed pyuria and his serum creatinine was $0.2 \mathrm{mg} / \mathrm{dl}$. Ultrasound showed gross left hydronephrosis with thinning of parenchyma and mild ureteric dilatation and left intravesical ureterocele (Fig. 1). Micturition cystogram showed the silhouette of the ureterocele in the postvoid film (Fig. 2). A diethylene triamine pentaacetic acid (DTPA) renogram showed a poorly functioning left kidney with differential function of $18 \%$ and a glomerular filtration rate (GFR) of $16 \mathrm{ml} /$ min along with obstructive drainage pattern with hold up at the pelviureteric junction (PUJ). A cross-sectional imaging in the form of magnetic resonance urogram (MRU) showed features suggestive of PUJ obstruction (Fig. 3). We made a provisional diagnosis of phimosis 


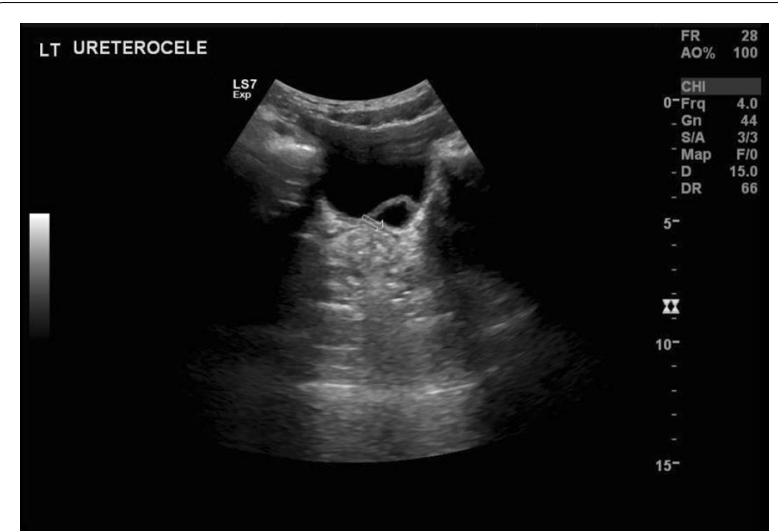

Fig. 1 Ultrasound image of bladder showing the intravesical ureterocoele (arrow)

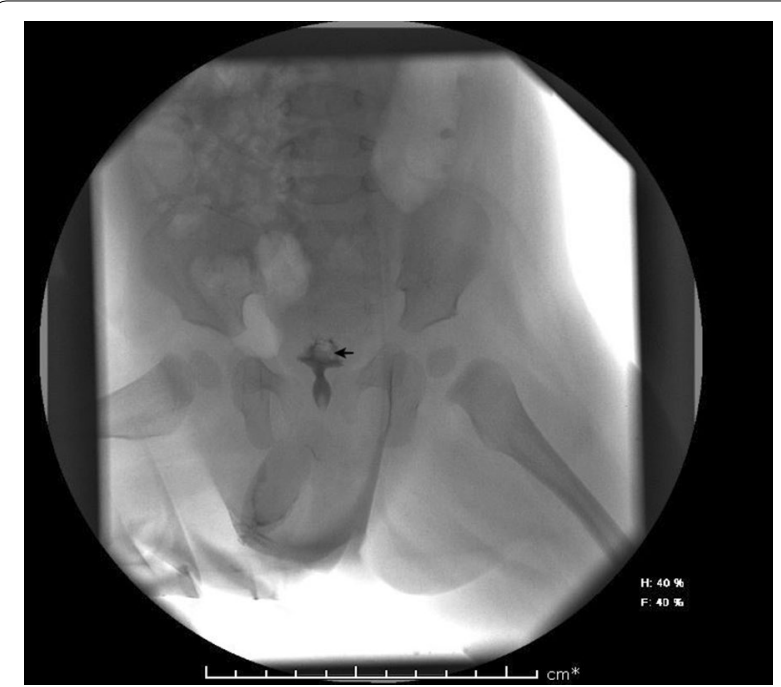

Fig. 2 Post-void film of micturition cystogram showing the silhouette of the left ureterocele within the bladder (black arrow)

with left-sided single system ureterocele with associated PUJ obstruction, and he underwent a circumcision with endoscopic ureterocele incision. Intraoperatively, retrograde pyelogram (RGP) was done by insertion of a $3 \mathrm{Fr}$ ureteric catheter through the opened out orifice showed complete blockage at level of upper ureter and it was not possible to pass a guidewire through the obstruction. Due to the tight obstruction at the PUJ, we proceeded to do an open pyeloplasty. Through a mini flank incision, the narrowed proximal ureteric segment was identified and resected and an Anderson Hynes dismembered pyeloplasty was performed. Examination of the resected segment showed a ureteric valve which was confirmed histologically. The patient did well postoperatively, and the stent was removed at 6 weeks. Ultrasound done at

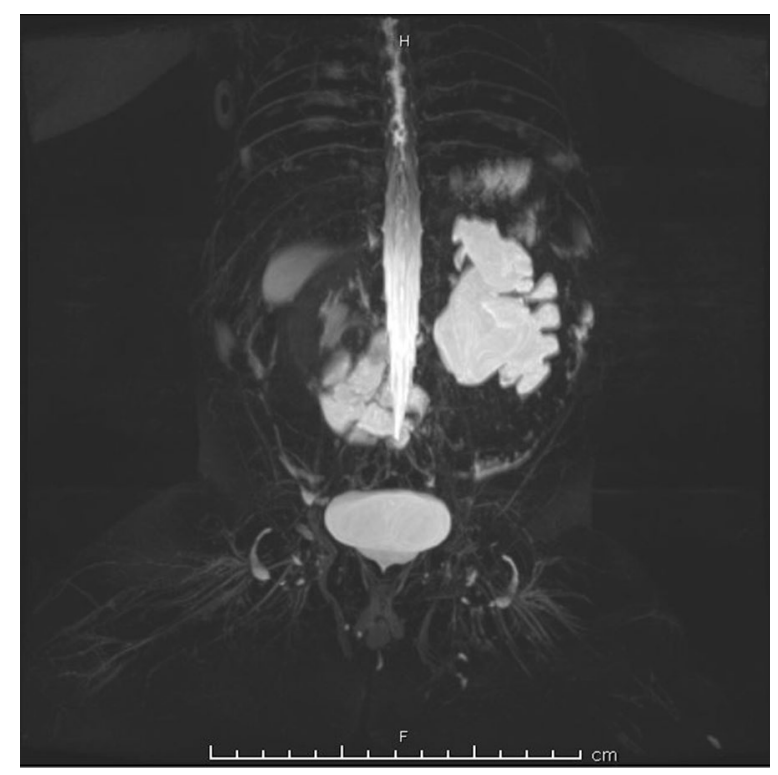

Fig. 3 Coronal view of magnetic resonance urogram showing left gross hydronephrosis with cutoff at pelviureteric junction

3 months showed marked reduction in hydronephrosis and improvement of cortical thickness. A. DTPA renogram showed good improvement in function to $35 \%$ with GFR of $34 \mathrm{ml} / \mathrm{min}$ with complete unobstructed drainage.

\section{Discussion}

Congenital ureteric valves are a rare cause of ureteric obstruction. Since the initial description by Wolfler in 1877 , till date, only 65 cases of ureteric valves have been reported [3, 4]. Rabinowitz has classified ureteric valves as Type I or Type II, based on the presence of smooth muscle within the leaflet or at the base only [5]. Morphologically, ureteric valves can be classified as cusp-like (leaflet) and diaphragmatic or annular type [1]. Our case was an annular type II ureteric valve, as demonstrated by histopathology.

The embryological basis of ureteric valves is still unclear. Few explanations regarding this do exist. Williams believes the valve situated at the upper ureter represents the persistence of exaggerated forms of fetal folds while the ones at the ureterovesical junction correspond to incomplete absorption of the Chwalla membrane. Chwalle's membrane is a double-layered epithelial membrane in the lower portion of the ureteric lumen and is a normal feature of ureteric development at 6 weeks of gestation. During the eighth week of gestation, the membrane ruptures under the pressure of urine excretion. Partial rupture of the membrane may result in a retained membrane that would constitute a ureteric valve. However, this theory does not explain multiple valves in one 
ureter or valves in the upper or mid-ureter [6-8]. More recently, several authors have directed attention to the frequent occurrence of associated ureteral anomalies in conjunction with ureteral valves. This is evidence that neither the fetal fold theory nor the Chwalle's membrane theory adequately explain ureteral valves and that the ureteral anomaly association points to a more generalized disturbance of ureteral bud development $[2,5,9]$.

Most common location for ureteric valve is the proximal ureter $(50 \%)$ followed by mid-ureter (17\%) and distal ureter (33\%) [6]. Ipsilateral multiple valves and bilateral valves have also been described [10].

Presentation in children is usually as antenatally detected hydronephrosis and in symptomatic patients, and the presenting symptoms include lump in the abdomen, flank pain and urinary tract infection [11]. A significant proportion of cases was not suspected clinically, and the correct diagnosis was made only peroperatively while managing suspected cases of ureteropelvic or ureterovesical junction obstruction.

Preoperative diagnosis with imaging is very difficult, and most of the time diagnosis can be made perioperatively only. Ultrasonography usually shows hydronephrosis and reveals associated urinary anomalies as in our case. Intravenous urogram can suggest the diagnosis if it shows hydroureteronephrosis until the valve. An isotopic renogram usually shows obstruction up to the level of valves. Micturition cystourethrogram is useful to rule out other associated anomalies like a reflux. MRU can accurately delineate anatomical abnormalities and has been useful in proper diagnosis in some patients $[12,13]$. Retrograde pyelography with delayed films is recommended in suspicious cases and will sharply define the obstructive area and demonstrate the normality below. The diagnosis in our case was suspected after RGP and was confirmed at surgery and by histological examination.

The ureteral valves must be differentiated from congenital ureteral strictures, which are rare, usually found in early adulthood, but can be often revealed by hydronephrosis on antenatal ultrasound. They correspond to a segmental ureteral fibrosis, usually associated with a smooth muscle hypoplasia. The ureteral lumen is usually narrow but sometimes can be of normal caliber. The stricture can be localized anywhere in the ureter [14].

The management of ureteral valves is mostly surgical and should be guided by complementary examinations. Treatment of ureteric valve depends on its location and the severity of renal deterioration. In case of salvageable kidneys, if the valve is near the ureteropelvic junction, a pyeloureteroplasty has been done. If close to the ureterovesical junction, a vesico-ureteral reimplant suffices. In other locations, removal of the ureteral segment which contains the valve has been done followed by an oblique ureteroureteral anastomosis. Endoscopic incision also has been described and is thought to be a safe and a feasible option [15].

Ureteric valves also have associated urinary anomalies in more than half of cases, including ureteric duplication, vesico-ureteral reflux, ectopic ureter and contralateral renal agenesis [2]. This suggests that perhaps ureteral valves are just another manifestation of a more complex faulty development of the ureteral bud. The association of ureteric valve with ureterocele has not been reported before. The diagnostic dilemma in such association is the fact that unlike, in usual cases of ureterocele where the ureter is dilated here in such cases of double obstruction the ureter is not as dilated, most probably due to the poor urine flow across the proximal obstruction. Regarding the treatment dilemma which pathology should be treated first, we believe that as shown in our index case, both can be treated at the same time successfully.

\section{Conclusion}

To conclude, congenital ureteral valves are a rare cause of ureteric obstruction and its association with ureterocele is rarer still. Identification of an ureterocele should not deter us from searching for an associated pathology like a ureteric valve when imaging shows more severe hydronephrosis suggestive of more proximal obstruction. This is all the more important as just relief of just distal obstruction and not the proximal high-grade obstruction will waste precious time leading to further renal detoriation and even irreversible damage to the kidney unit.

\section{Acknowledgements \\ None.}

Authors' contributions

AD contributed to manuscript writing, PAS contributed to manuscript writing and editing, HP contributed to manuscript editing. All authors have read and approved the manuscript.

\section{Funding}

This research did not receive any specific grant from funding agencies in the public, commercial, or not-for-profit sectors.

Availability of data and materials

Not applicable.

Compliance with ethical standards

Ethics approval and consent to participate

Not applicable.

Consent for publication

Written consent has been obtained from parents of patient for publication.

Competing interests

The authors declare that they have no competing interests. 
Received: 8 May 2020 Accepted: 16 September 2020

Published online: 10 November 2020

\section{References}

1. Gupta RK, Borwankar SS, Parelkar SV (2008) Ureteric valve: case report with an insight into anatomy, embryology, presentation and management. Indian J Urol 24(4):561-563

2. Mendelsohn C (2009) Using mouse models to understand normal and abnormal urogenital tract development. Organogenesis 5(1):306-314

3. Vedpalsingh TH, Vijay JA, Gorakhnath WV, Vilas BM, Omprakash DS (2015) Congenital bilateral mid ureteral stenosis: a rare finding. J Clin Diagn Res 9(5):3-4

4. Rossi E, Salas JR, Aucatoma FC, Muñoz MO, Fochs LM (2007) Congenital ureteral valves: two new cases and a review of the literature. J Pediatr Urol 3:344-349

5. Alhazmi H, Neel AF (2018) Congenital mid-ureteral stricture: a case report of two patients. BMC Urol 18(1):108

6. Nouira Y, Feki W, Kallel Y, Mekni A, Haouet S, Horchani A (2006) Ureteric valves: a report of two cases. Ann Chir 131(9):567-570

7. Hamid R, Bhat NA, Rashid KA (2015) Congenital midureteric stricture: challenges in diagnosis and management. Case Rep Urol 2015:969246. https://doi.org/10.1155/2015/969246

8. Manzoni C (2002) Ureteral valves. Rays 27:87-88
9. Radmayr C, Fritsch H, Schwentner C et al (2005) Fetal development of the vesico-ureteric junction, and immunohistochemistry of the ends of refluxing ureters. J Pediatr Urol 1(2):53-59

10. Daher P, Riachy E, Mourani C, Smayra T, Haddad S (2007) An unusual case of bilateral primitive obstructed megaureters due to ureteric valves presenting with anuria at the age of 1 month. J Pediatr Surg 42:17-20

11. Woolf AS, Winyard PJ (2002) Molecular mechanisms of human embryogenesis: developmental pathogenesis of renal tract malformations. Pediatr Dev Pathol 5:108-129

12. Ghribi A, Jouini R, Hellal Y, Maazoun K, Njim L, Krichene I et al (2009) Congenital ureteral valve associated with contralateral renal agenesis. Eur J Pediatr Surg 19:339-340

13. Gattan-Smith JD, Jones RA, Little S, Kirsch AJ (2011) Bilateral congenital midureteric strictures associated with multicystic dysplastic kidney and hydronephrosis: evaluation with MR urography. Pediatr Radiol 41:117-120

14. Hwang AH, McAleer IM, Shapiro E, Miller OF, Krous HF, Kaplan GW (2005) Congenital mid ureteral strictures. J Urol 174:1999-2002

15. Aslam MZ, Gowda BDR (2010) Holmium laser ablation: a successful treatment option for an obstructing ureteric valve. Can Urol Assoc J 4(1):15-16

\section{Publisher's Note}

Springer Nature remains neutral with regard to jurisdictional claims in published maps and institutional affiliations.

\section{Submit your manuscript to a SpringerOpen ${ }^{\circ}$ journal and benefit from:}

- Convenient online submission

- Rigorous peer review

- Open access: articles freely available online

- High visibility within the field

- Retaining the copyright to your article

Submit your next manuscript at springeropen.com 